\section{Clinital Mtotes:}

\section{MEDICAL, SURGICAL, OBSTETRICAL, AND THERAPEUTICAL.}

A CASE OF MITRAL STENOSIS; DEATH FROM EMBOLISM OF SIX MAIN ARTERIES.

By Richard S. Roper, M.R.O.S. ENG., L.R.C.P. LOND.

A MAN, aged 27 years, was admitted to the St. Marylebone Infirmary on Oct. 26th, 1905, suffering from cardiac disease and bronchitis. He had had rheumatic fever twice. On admission he complained of cough but otherwise seemed in fair healtb. On examination there were a few râles and rhonchi scattered over both lungs. The cardiac area of dulness was increased and on auscultation well-marked systolic and mid-diastolic bruits were heard at the apex. No other bruits were heard. The pulse was regular and of good volume. The liver was not enlarged, neither was there any ascites, œdema, or other sign of failing compensation. The patient was kept in bed for a month and as at the end of that time all physical signs in the lungs had subsided he was allowed up and by Dec. 7th was up all day.

On Dec. 7th, at 4.45 P.M., while in the day-room the patient suddenly became very ill and was at once removed to bed. When examined he was blue, pulseless, cold, and clammy, and was struggling vigorously, and at the same time complained of great pain in his legs. The heart was beating regularly and at normal rate but no bruits could be heard. At 7 P.M. the general appearance of the matient was much the same and the condition of collapse was very little improved. He still complained of great pain in the knees and abdomen. Neither tibial pulse could be felt nor was there any pulse at the left wrist. The left femoral artery could be felt pulsating just below Poupart's ligament. Both lower limbs and the left arm were paralysed. There was anæsthesia of the legs as far up as Poupart's ligament. The abdomen was slightly distended. At no time was he unconscious and his mental condition was quite clear. A sixth of a grain of morphine acetate was given and at 10 P.M. he had somewhat recovered and had less pain. At this time his face was a natural colour, the collapse had passed off, and he was warm. He was still unable to move mis left arm but motor power and sensation had returned to the lower limbs. The right radial was the only artery felt pulsating in the limbs. The abdomen now was very diswended and a copious blood stained motion was passed. Several ounces of blood were passed per rectum until death, which took place at 4 A.M. on Dec. 8th.

A post-mortem examination was made seven hours after death. There was hypertrophy of the left auricle and ventricle with marked stenosis of the mitral orifice. The latter just admitted the tip of one finger. Recent vegetations were present on the inner wall of the left auricle of the size of a pea. No ante-mortem clot was to be seen. The small intestines were distended and anæmic. Embolism of the following arteries was found: both common femorals with ante-mortem clot extending as far as the popliteal artery; the right internal iliac at its bifurcation; the right renal at its division; the superior mesenteric just below the middle colic branch; and the left brachial at the origin of the superior profunda. No other pathological condition was found in any organ.

I am indebted to Mr. J. R. Lunn, medical superintendent, for permission to publish this case.

Notting Hill, w.

\section{A CASE OF LEUK WITH ARSENIC.}

By Frank Lindsay Dickson, M.B., Сh.B.Glasg.

THE patient in the following case was a man, aged 24 years, who came to me on May 30th complaining of pain in the back, slight headache, and general debility. His temperature was $99.6^{\circ} \mathrm{F}$. and I gave him a saline mixture 'with orders to rest'for a few days. He'returned three days later and stated that the pain in the back was better but that he felt very weak. His temperature was normal and I treated the case as debility following influenza, prescribing compound syrup of the hypophosphites and codliver oil. At the same time I noticed a slight swelling of one of the deep cervical glands. This was hard, freely moveable, and quite painless. The patient then took to his bed, there being great prostration. The glandular enlargement ircreased until the swelling was of about the size of a hen's egg. His temperature remained normal and there was no improvement in his general condition.

On the evening of June 6 th I found that the inguinal, right axillary, and post-cervical glands were slightly enlarged; the splenic area of dulness was slightly increased and pain was induced on pressure over that organ. I was inclined to diagnose the case as one of pseudo-leukæmia, true leukæmia to be left for consideration after examination of the blood, for which purpose I sent him to the Queen's Hospital, Birmingham. The patient was seen by Dr. J. G. Exanuel, who afterwards told me that he was inclined to regard the case as one of mild enteric fever. A blood film was, however, taken and on the next morning I received from Dr. Emanuel a letter from which the following is an extract: "There is a great excess of leucocytes and lymphocytes, the latter predominating. I regard it as being one of those rare cases of acute or subacute lymphatic leukrmia. I expect it will terminate fatally in a few weeks." I examined the blood myself on the following day and found that the white cells were almost as numerous as the red ones. I then commenced to administer liquor arsenicalis, giving five minims three times a day, and the result seemed almost miraculous. After three days the patient "felt much better in himself," the glandular swellings were noticeably less, and I found that there was marked improvement in the condition of the blood. The dose of liquor arsenicalis was increased rapidly unti 15 minims were being taken thrice daily, the improvement continuing and no toxic symptoms being produced by the drug. The patient had one attack of epistaxis which weakened him a little; he had, however, been subject to these attacks from childhood. About a fortnight later the glands were practically normal and the blood was, in my opinion, in a like condition. Dr. Emanuel came to see him after I had written my opinion on the subject and took half a dozen films of the blood. His next letter said that "the blood is practically normal."

The dose of arsenic was gradually diminished and on July 6th the patient went to the seaside for a fortnight, taking with him sufficient medicine to last him till his return. I gave him iron in addition to the arsenic as the red blood corpuscles needed a little recruiting. On his return be told me that he felt as well as ever he had done in his life. Two days later he returned to his work as a carpenter and he has remained perfectly well ever since. The only predisposing cause was that some time before the commencement of the illness he had been working about some waterclosets of which the drains were obstructed and the odours not ambrosial.

Hay Mills, Birmingham.

\section{A CASE OF RUPTURE OF THE GRAVID FALLOPIAN TUBE.}

BY N. J. F. VAZIEDAR.

THE patient was an ayah, aged 25 years, who was admitted into the Sir Jamsetjee Jeejeebhoy Hospital in Bombay on Dec. 9th, 1905, for acute intestinal obstruction. The history of her illness was that on Dec. 6th, whilst micturating, she was suddenly seized with an acute pain in the abdomen after which she vomited and fainted. The pain and vomiting increased and on the 8 th the vomited matter became fæcal. There was absolute con stipation in addition to which no flatus had been passed since the 6th. On admission she was in a collapsed con. dition. Her temperature was $97^{\circ} \mathrm{F}$., her pulse was 146 per minute and very weak, and her respirations were 48 per minute; the abdomen was much distended all over, tense and hard on palpation, and tympanitic on percussion. There was almost continuous freal vomiting. The case being diagnosed as one of acute intestinal obstruction, probably due to a volvalus, a median laparotomy was immediately 